\title{
Artificial intelligent techniques based on direct torque control of induction machines
}

\author{
Mona Magdy, Salama Abu-Zaid, Mahmoud A. Elwany \\ Department of Electrical Engineering, Al-Azhar University, Cairo, Egypt
}

\begin{tabular}{l} 
Article Info \\
\hline Article history: \\
Received Jan 15, 2021 \\
Revised Sep 9, 2021 \\
Accepted Sep 23, 2021 \\
\hline
\end{tabular}

Keywords:

Artificial neural networks

Direct torque control

Fuzzy logic control

Induction motor drive

Vector control

\begin{abstract}
The direct torque control (DTC) system, which is based on induction machine drive is a developed and simple control method. It allows high dynamic performance with very simple hysteresis control scheme; However, its disadvantages are high current, torque, and flux ripple. In this paper, DTC of induction machine drive has been improved by using the applications of artificial intelligence (AI) approaches to reduce the current, torque, and flux ripples and also get better performance of the machines. At the conclusion of this study, the outcomes of traditional DTC and artificial intelligent methods are compared. By the program MATLAB/Simulink, the modeling and simulation results of the DTC system for induction machine (IM) have been proposed.
\end{abstract}

This is an open access article under the CC BY-SA license.

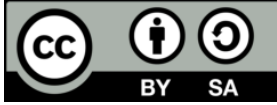

Corresponding Author:

Mona Magdy

Departement of Electrical Engineering

Al-Azhar University

Tanta, Al-Gharbiyah, Egypt

Email: mona.magdy973@yahoo.com

\section{INTRODUCTION}

Electrical engines are one of the most pertinent components in electricity industry [1]. Induction Motors are generally utilized in industries due to low cost, less maintenance and hardness, so it plays a significant job in the world. There are two fundamental sorts of induction motors which are the squirrel-cage and the wounded rotor. Both of them are used, However Squirrel-cage is considered more dependable and less expensive to make [2].

Speed control is a significant issue because it is constantly attempted to reach to the attractive reaction in short time. Changing pole numbers and voltage control. Some of these techniques are presently out of utilization. Nowadays, vector control or field-oriented control (FOC) is used to solve the issue of controlling the speed of motor by changing the voltage and the frequency [3].

The most famous induction motor drive control strategy is the FOC or (vector control). FOC empowers induction motor control similarly to separately excited direct current (DC) motors [4]. Vector control is more specified than scalar control since the controlling of torque and flux is decoupled, so it utilized in high-performance drives [5]. The principle advantages of vector control are high dynamic performance, lower torque ripple, and switching frequency. Vector control have disadvantages that are needed for two co-ordinate transformations, current controllers, and rise machine parameter instability [6]. To play out the vector control method, it's important to break down the stator current phase into two symmetrical parts in a synchronously rotating reference edge and this requires two transformations, Clarke and Park transformation. 
Vector control have two techniques for induction motors, one of them is the direct field oriented and the other is the indirect field Oriented [7]. More than 10 years back, DTC was acquainted with give a quick and great unique torque performance and it can be viewed as just an option in contrast to such the FOC method. The design of DTC considered is a lot less complex than the system of FOC because of none of the frame transformer. It additionally needn't a pulse width modulator or a position encoder [8]-[10]. The artificial intelligence (AI) techniques are equipped for learning the ideal mapping between the framework's inputs and outputs signals without the need for understanding the framework's definite numerical model. It can be considered as rearranged numerical models of mind-like systems and they work as parallel circulated registering systems [11], [12]. AI techniques, like expert-system (ES), fuzzy logic (FL), artificial neural network (ANN or NNW), and genetic algorithms (GA) have as of late been used broadly responsible for induction motor drives. AI appears to have more noteworthy effect on power gadgets, electronics of the engine, and motor drives region which is obvious through the productions in the writing. AI-based induction machine drives having gotten more noteworthy consideration, Since the century $1990 \mathrm{~s}$. Apart from the existing control techniques, intelligent control strategies, for example, FL control, GA, NN control, and ES demonstrated to be unrivaled. AI controller may be the better controller for induction machines [13]-[18].

\section{PRINCIPLE OF DIRECT TORQUE CONTROL}

Figure 1 illustrates a diagram of conventional DTC of induction motor drive, where $\left(\varphi s^{*}, \mathrm{Te}^{*}\right)$ are the reference values of flux and torque, $(\varphi \mathrm{s}, \mathrm{Te})$ are estimated the values of stator flux and torque. " $\theta \mathrm{s}$ is the stator flux angle, $\omega$ is the real speed value, and $\omega^{*}$ is the command speed value". Method of DTC can be performed where two hysteresis controllers can be used (one for torque and another for flux), estimators of torque and flux, and a switching table can be used to determine the suitable voltage vector [19]. The inverterfed machine's torque is controlled by hysteresis control of torque size and stator flux, which chooses one of six active voltage vectors and two zero voltage inverters [20]. Switching table for selecting voltage vectors using for choosing rapid torque reaction, low inverter switching frequency, and low harmonic losses without the complicated field orientation by restricting flux and torque errors with the optimum range inside the corresponding flux and torque hysteresis regions [19]. Figure 2 shows the diagram of PI controller used to calculate the reference torque due to the difference between the motor's instantaneous speed and the reference.

DTC concept depends on choosing the optimum voltage vector to spin the flux and generate the needed torque. In a voltage feed three phases, the switching commands from every inverter leg are complementary. So, by each leg a logic condition $\mathrm{Ci}(\mathrm{i}=\mathrm{a}, \mathrm{b}, \mathrm{c})$ may be created, withlindicating that the upper switch is commanded to be closed and 0 indicating that the lower one is commanded to be closed [21] .

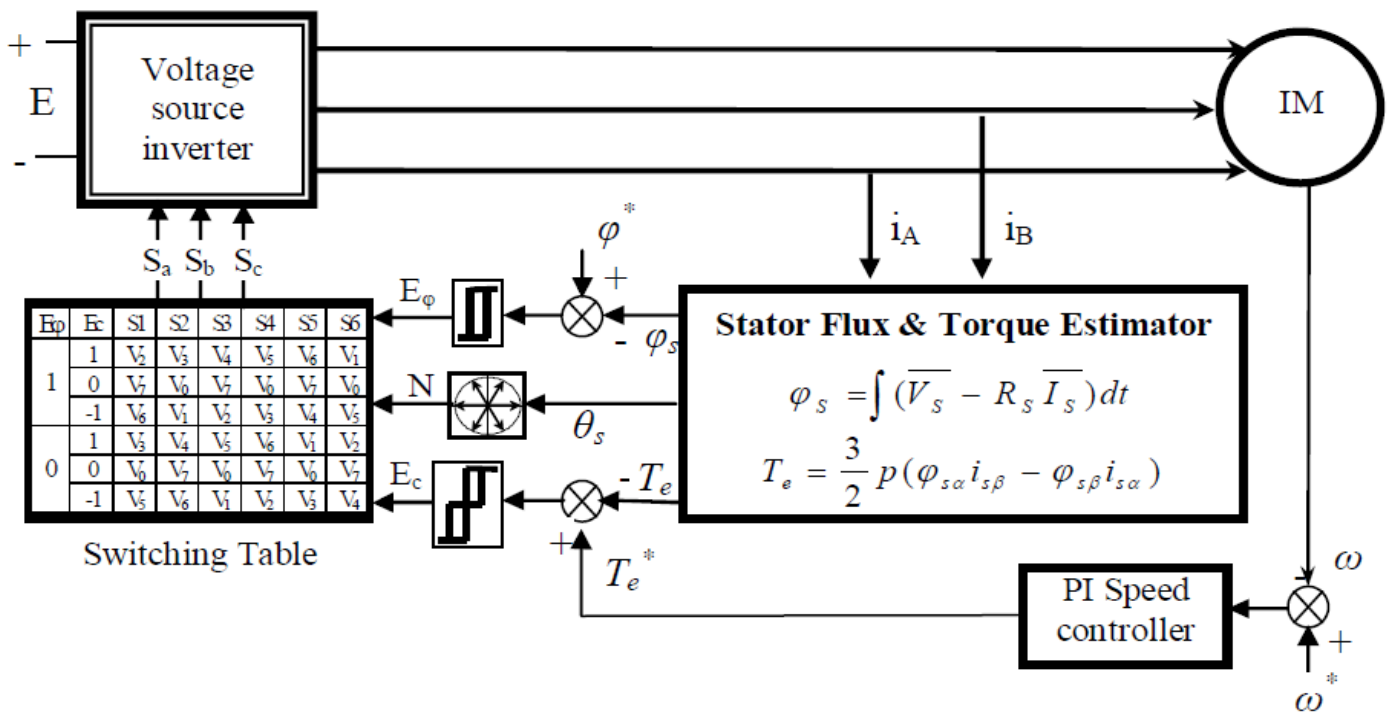

Figure 1. Graph of the DTC technique 


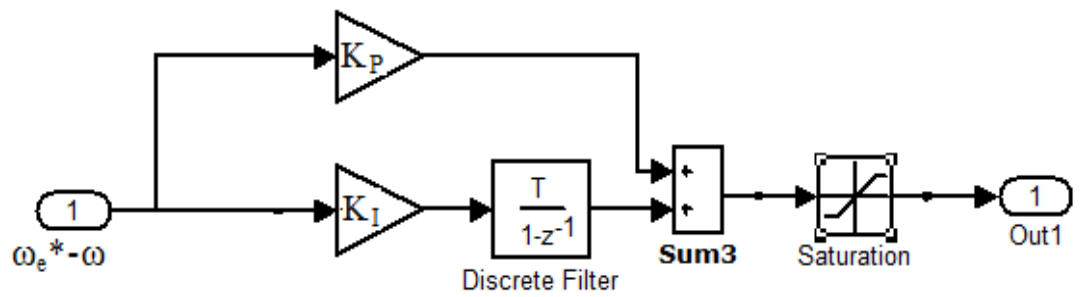

Figure 2. A speed PI controller diagram

Voltage vectors can be expressed by the following equation:

$$
V_{s}=\sqrt{\frac{2}{3}} U_{0}\left[C_{1}+C_{2} e^{\frac{j 2 \pi}{3}}+C_{3} e^{\frac{j 4 \pi}{3}}\right]
$$

Per (1), there are eight switching regions: one of them is two zero voltage vectors and the other is six non-zero voltage vectors, as shown in Figure 3. Figure 3 shows the torque is explained by a quadrature axis and the stator flux is explained by a direct axis. As can be seen, choosing a suitable voltage vector results in preserve the torque and stator flux inside acceptable bounds.

Takahashi recommended the Table 1 for switching of conventional DTC. Feedback torque and flux are determined of the voltages and currents of the machine terminal and the block for signal calculation computes the number of the sector where the flux vector is now located. There are six effective voltage vectors every spanning. The voltage vector table takes the flux value, torque value, and section number and uses a look-up table to provide suitable control for the inverter, as shown in Table 1 [21].

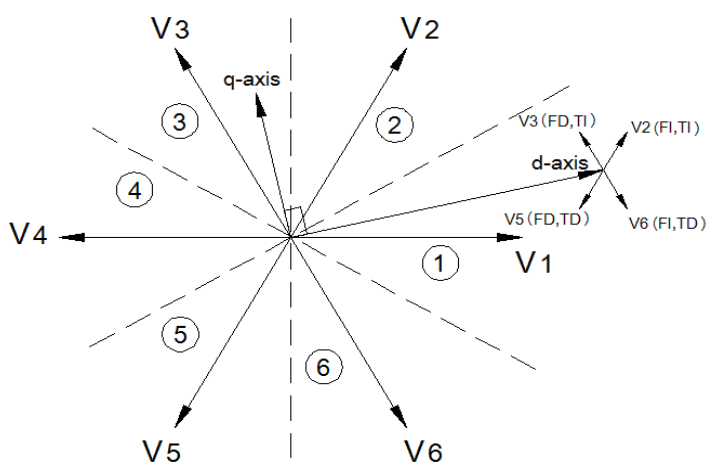

Figure 3. The dq level is divided into six

Table 1. Conventional DTC switching table sections angular

\begin{tabular}{llllllll}
\hline \multicolumn{2}{c}{ Sector } & \multirow{2}{*}{2} & \multirow{2}{*}{3} & \multirow{2}{*}{5} \\
$\mathrm{H}_{\mathrm{Te}}$ & $\mathrm{H}_{\Psi}$ & 1 & 2 & 3 & 4 & 5 & 6 \\
\hline 1 & 1 & $\mathrm{~V}_{1}$ & $\mathrm{~V}_{6}$ & $\mathrm{~V}_{5}$ & $\mathrm{~V}_{4}$ & $\mathrm{~V}_{3}$ & $\mathrm{~V}_{2}$ \\
0 & & $\mathrm{~V}_{7}$ & $\mathrm{~V}_{0}$ & $\mathrm{~V}_{7}$ & $\mathrm{~V}_{0}$ & $\mathrm{~V}_{7}$ & $\mathrm{~V}_{0}$ \\
-1 & & $\mathrm{~V}_{5}$ & $\mathrm{~V}_{4}$ & $\mathrm{~V}_{3}$ & $\mathrm{~V}_{2}$ & $\mathrm{~V}_{1}$ & $\mathrm{~V}_{6}$ \\
1 & -1 & $\mathrm{~V}_{2}$ & $\mathrm{~V}_{1}$ & $\mathrm{~V}_{6}$ & $\mathrm{~V}_{5}$ & $\mathrm{~V}_{4}$ & $\mathrm{~V}_{3}$ \\
0 & & $\mathrm{~V}_{7}$ & $\mathrm{~V}_{0}$ & $\mathrm{~V}_{7}$ & $\mathrm{~V}_{0}$ & $\mathrm{~V}_{7}$ & $\mathrm{~V}_{0}$ \\
-1 & & $\mathrm{~V}_{4}$ & $\mathrm{~V}_{3}$ & $\mathrm{~V}_{2}$ & $\mathrm{~V}_{1}$ & $\mathrm{~V}_{6}$ & $\mathrm{~V}_{5}$ \\
\hline
\end{tabular}

\section{DIRECT OF TORQUE CONTROL USING FUZZY LOGIC}

\subsection{Principles of fuzzy torque control}

A fuzzy logic is presented in this section to decrease torque ripple while improve motor performance. The fuzzy controller, which replaces the switching table in the conventional DTC, achieves this goal. A diagram of the FL- DTC method of the induction motor is show in Figure 4. Generally, fuzzification, 
fuzzy reasoning, and defuzzification are the three major components of a fuzzy controller. A membership function is used to do the fuzzification. Fuzzy controller's effectiveness is based on both the membership function shape and the fuzzy reasoning rules. A functional diagram using controller of fuzzy logic is shown in Figure 5.

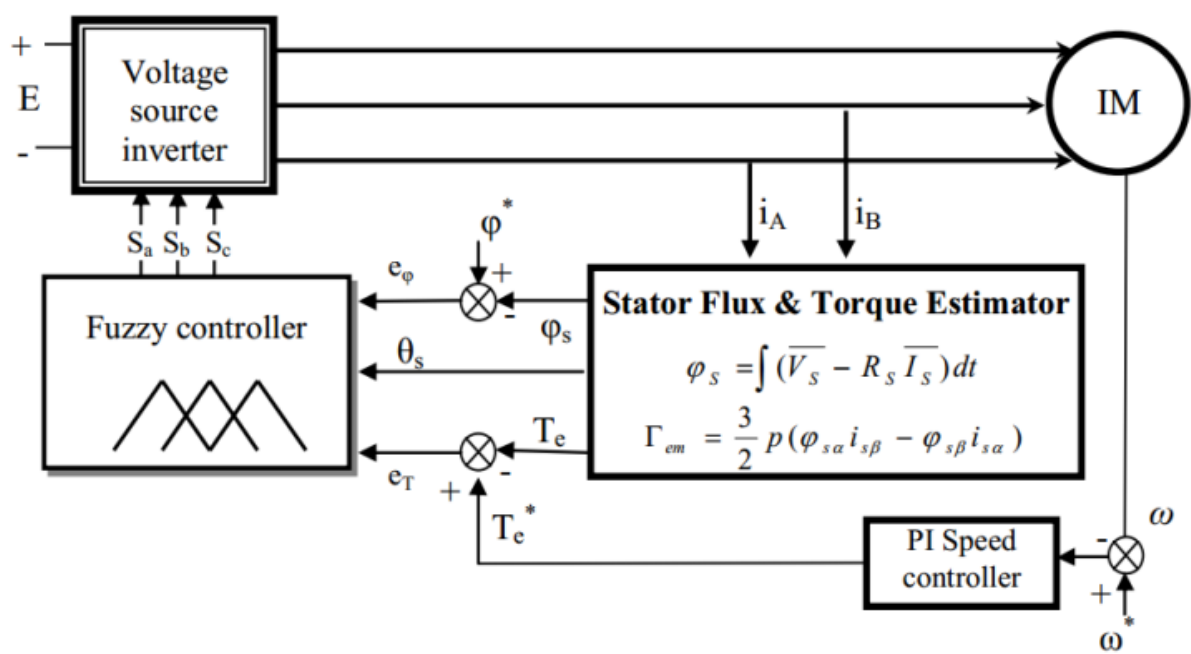

Figure 4. DTC diagram using controller of fuzzy logic

The flux error of stator, electromagnetic torque error, and the stator flux angle are the three input variables, while the stator voltage vector is output. The input and output variables are called fuzzy varibles.

\subsection{Fuzzy control rules}

Figure 5 shown how decisions are made based on the inputs and the rule basisq. The rules for the control approach used for the system to be controlled are entered into a data base by a Fuzzy Logic Control designer. The fuzzy logic DTC rules are applied to the twelve sectors DTC.

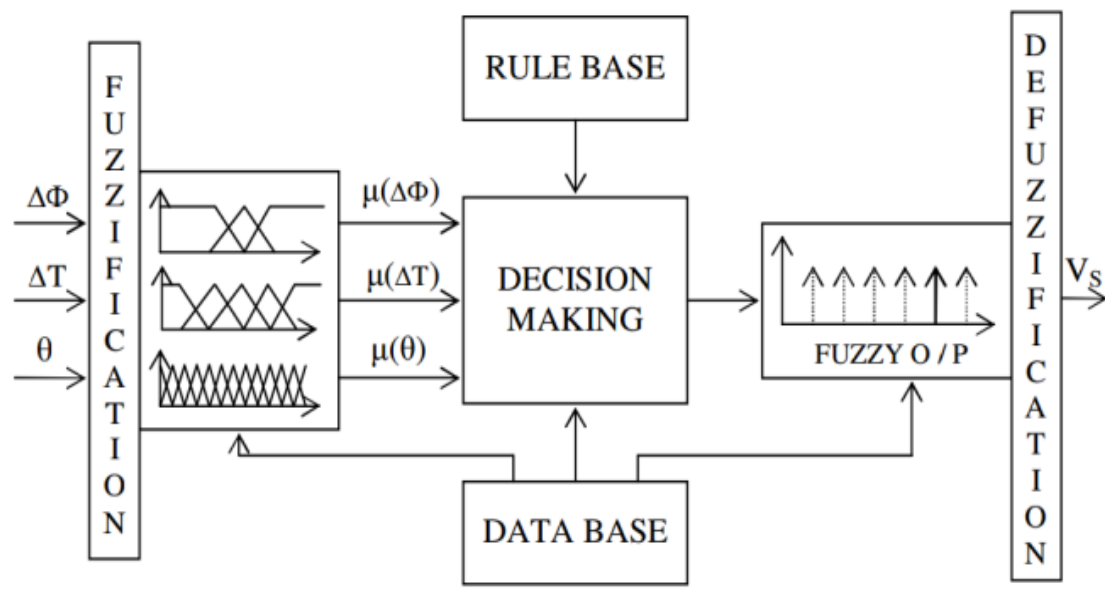

Figure 5. A functional diagram using controller of fuzzy logic

\section{ARTIFICIAL NEURAL NETWORKS}

4.1. Artificial neural networks principles

Artificial neural networks (ANNs) are machines that mimic the human brain's learning and generalization abilities. Despite not understanding the system's exact mathematical model, the ANNs can 
discover the optimal mapping between the system's outputs and input signals [22]. A neuron's mathematical model is given by:

$$
\mathrm{y}=\phi\left(\sum_{i=1}^{N} \mathrm{Wi} * \mathrm{Xi}+\mathrm{b}\right)
$$

Where $(\mathrm{x} 1, \mathrm{x} 2 \ldots \mathrm{xN})$ are the neuron input signals, the corresponding weights are $(\mathrm{w} 1, \mathrm{w} 2, \ldots \mathrm{wN})$, and the bias parameter is $\mathrm{b}$. A tangent sigmoid function is $\Phi$, and $\mathrm{y}$ is the neuron's output signal. The neurons that match to the computational nodes are the essential components of an ANN. Every node uses constant weights to multiply its input signals, summarizes the result and maps the summition to a nonlinear function; then the result is transferred to its output and integrated an activation function is as illustrated in Figure 6. The ANN is illustrated in Figure 7, it may be trained to perform a particular role by changing the values of the interconnections (weights) between elements [23]. Usually, neural networks are modified or educated so that a given input contributes to a desired output [24].

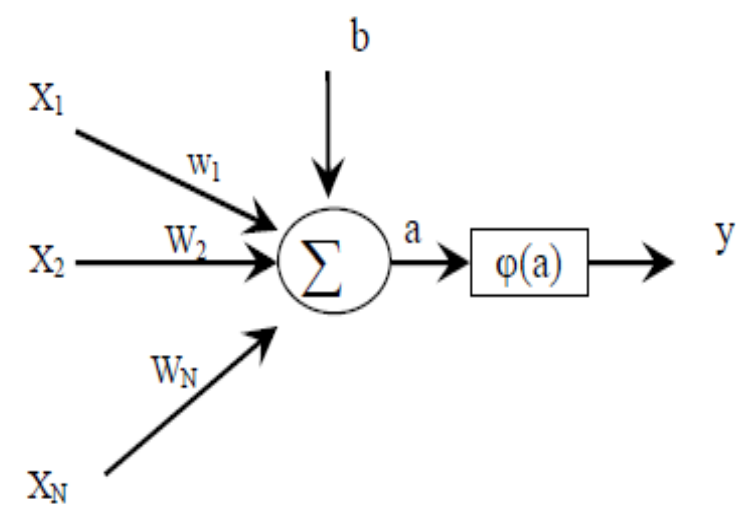

Figure 6. Representation of the artificial neuron

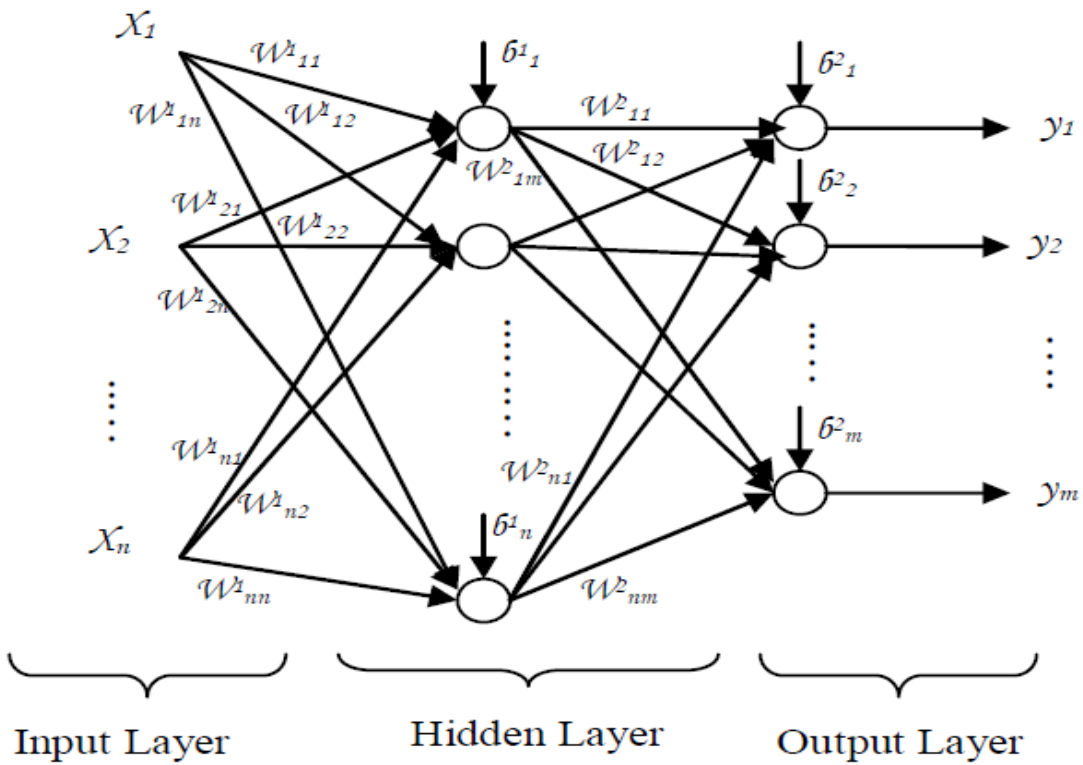

Figure 7. Structure of neural network

\subsection{ANN structure for DTC}

In direct torque control, the artificial neural network may be employed in two methods:

- To achive the desired response, replace the standard PI speed controller. A feed forward network with three hidden and one output layer, as well as one input, is provided. The transfer functions for the buried 
layers are 'log-sigmoid,' 'tan-sigmoid,' and 'pure line.' MATLAB simulink is used to train the LevenbergMarquardt Back-propagation algorithm with 20 neurons in every hidden layer.

- The switching table selector component and the two hysteresis controllers are replaced. The ANN inputs, the difference between the estimated electromagnetic torque, the reference torque, and the position of the flux stator vector specified by the associated sector number, all contribute to the inaccuracy between the estimated flux value and its reference value. Three neurons make up the ANN output layer. Every neuron represents one of the three vector pairs that will be used to drive the induction motor [25], [26]. Figure 8 shows the design of DTC using ANN techniques as a switching state selector. The rest of the system is identical to DTC's conventional structure, as seen in Figure 1.

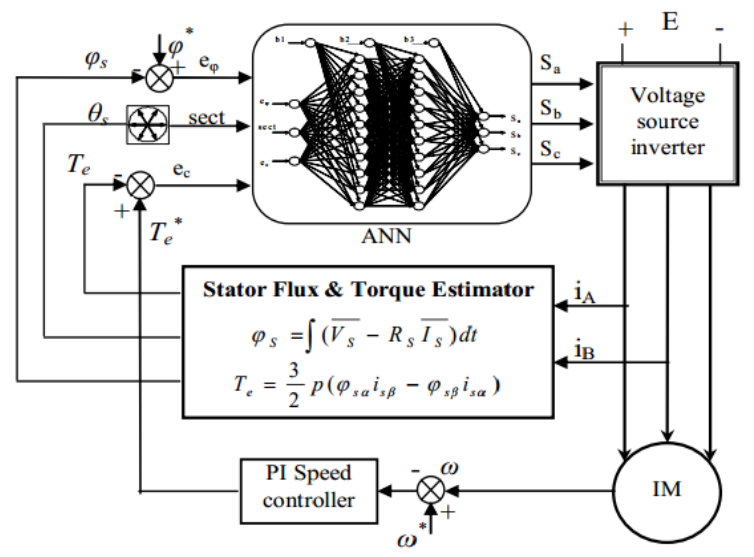

Figure 8. Design of DTC using ANN techniques

\section{SIMULATION MODEL AND RESULTS}

\subsection{Model and parameters}

Figure 9 shows the DTC simulink model for induction motor drive. The model was created using the blocks from the MATLAB program. Table 2 shows the parameters of the induction motor. After running models, the comparison between ripple values shows in Table 3 .

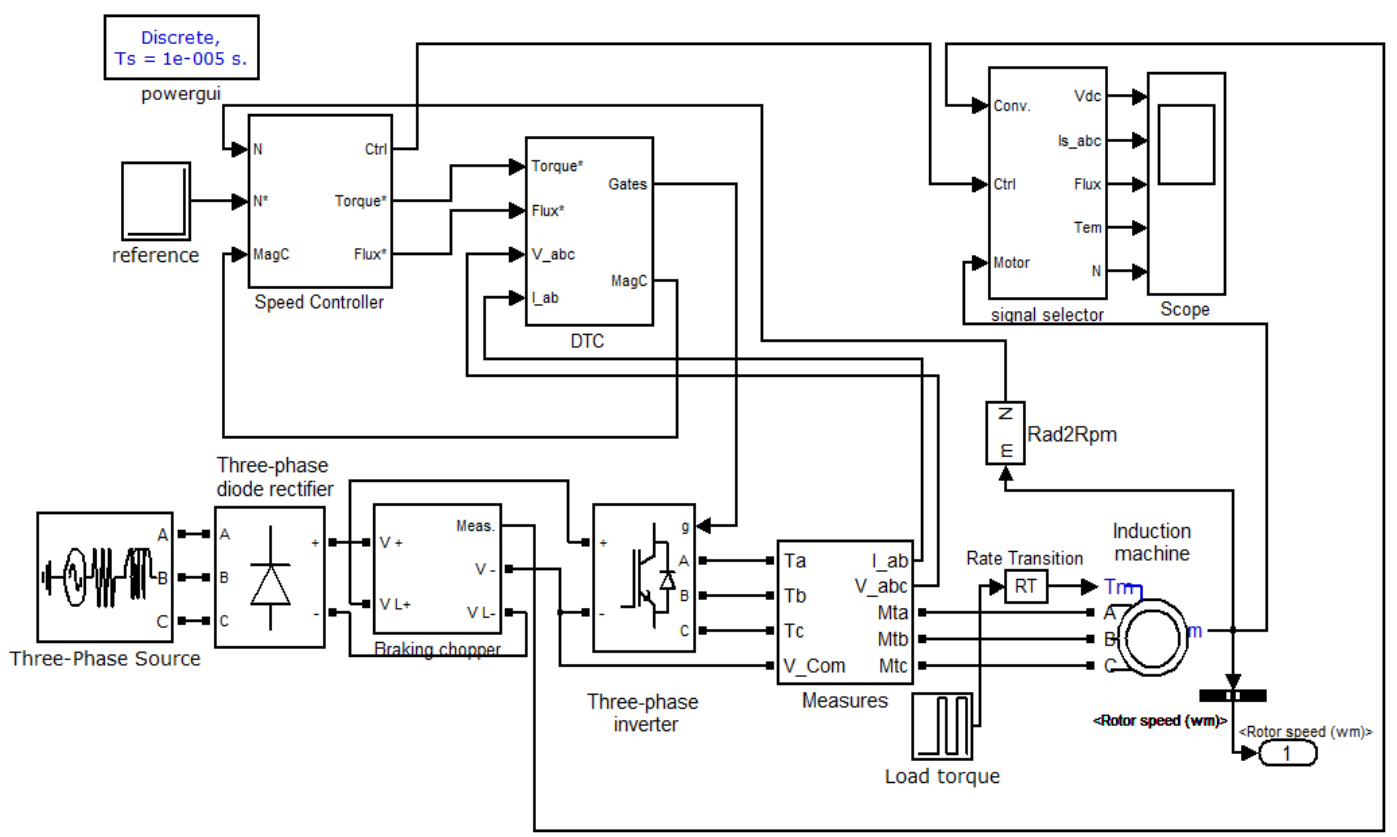

Figure 9. DTC model for induction motor drive in Simulink 
Table 2. Parameters for I.M

\begin{tabular}{lcc}
\hline Variable & Symbol & Value (unit) \\
\hline Rated voltage & $\mathrm{P}$ & $220 \mathrm{~V}$ \\
Rated power & $\mathrm{V}$ & $2238 \mathrm{VA}$ \\
Rated frequancy & $\mathrm{F}$ & $50 \mathrm{HZ}$ \\
Pole pairs & $\mathrm{P}$ & - \\
Resistance of stator & $\mathrm{Rs}$ & $0.435 \Omega$ \\
Inductance of stator & $\mathrm{Ls}$ & $2 \mathrm{mH}$ \\
Resistance of rotor & $\mathrm{Rr}$ & $0.816 \Omega$ \\
Inductance of rotor & $\mathrm{Lr}$ & $2 \mathrm{mH}$ \\
Mutual inductance & $\mathrm{Lm}$ & $69.31 \mathrm{mH}$ \\
\hline
\end{tabular}

Table 3. Comparison between ripple values for DTC methods

\begin{tabular}{lcc} 
& Tourque & Flux Current \\
\hline Switching Table for CDTC & 0.45 & 0.030 .47 \\
Fuzy Logic Control & 0.25 & 0.010 .41 \\
ANN Replace Conventional PI & 0.35 & 0.0290 .4 \\
ANN Replace Switching Table & 0.4 & 0.0280 .4 \\
\hline
\end{tabular}

\subsection{Electromagnetic torque results}

\subsubsection{Rotor speed results}

Figures 10-13 show the results of rotor speed for DTC. Figure 10 using classical, Figure 11 by using fuzzy logic. ANN shows in Figure 12 by replacing PI and in Figure 13 by replacing the switching table.

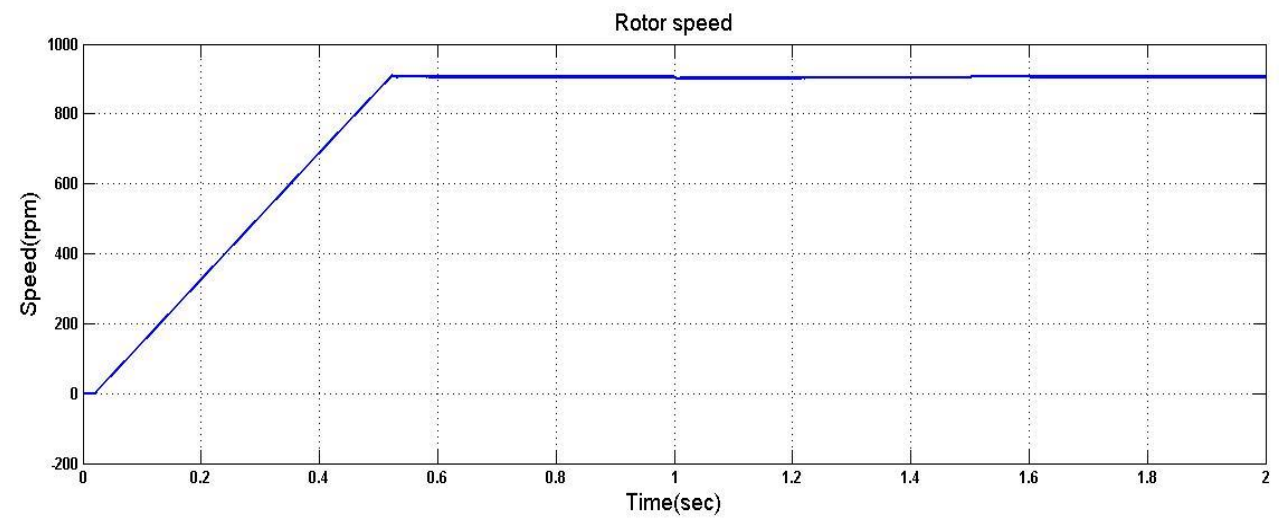

Figure 10. Rotor speed for the classical DTC

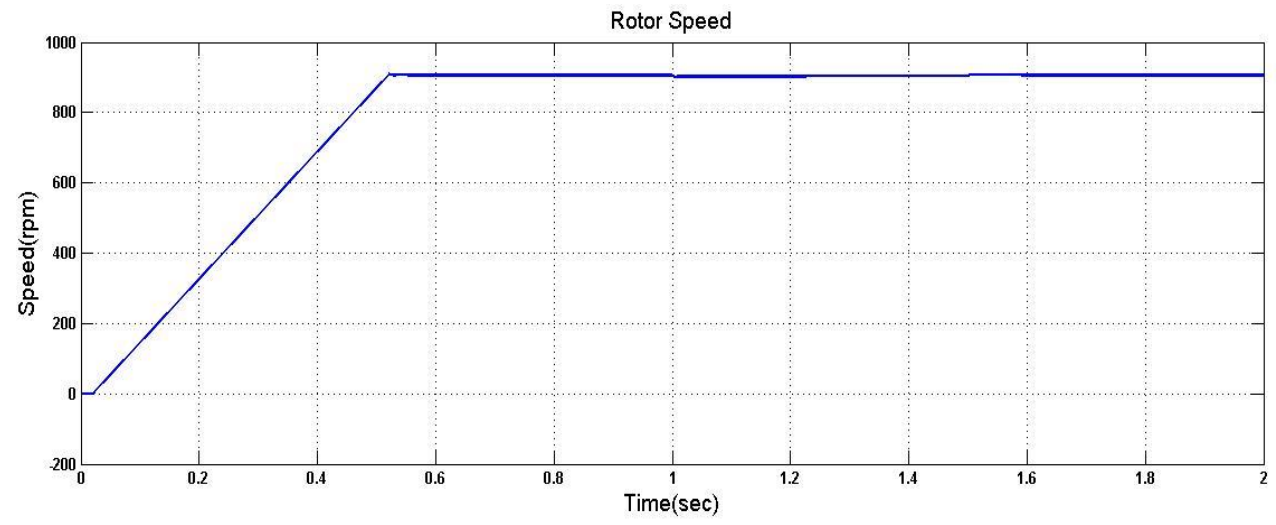

Figure 11. Rotor speed for DTC using fuzzy logic 


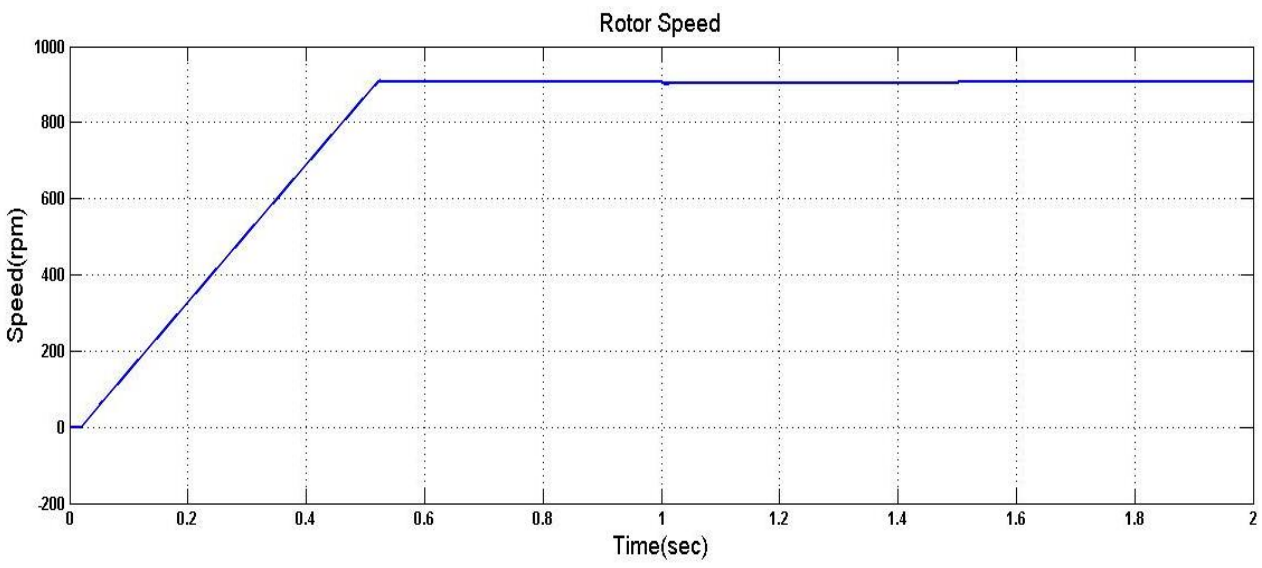

Figure 12. Rotor speed for DTC using ANN by replacing conventional PI

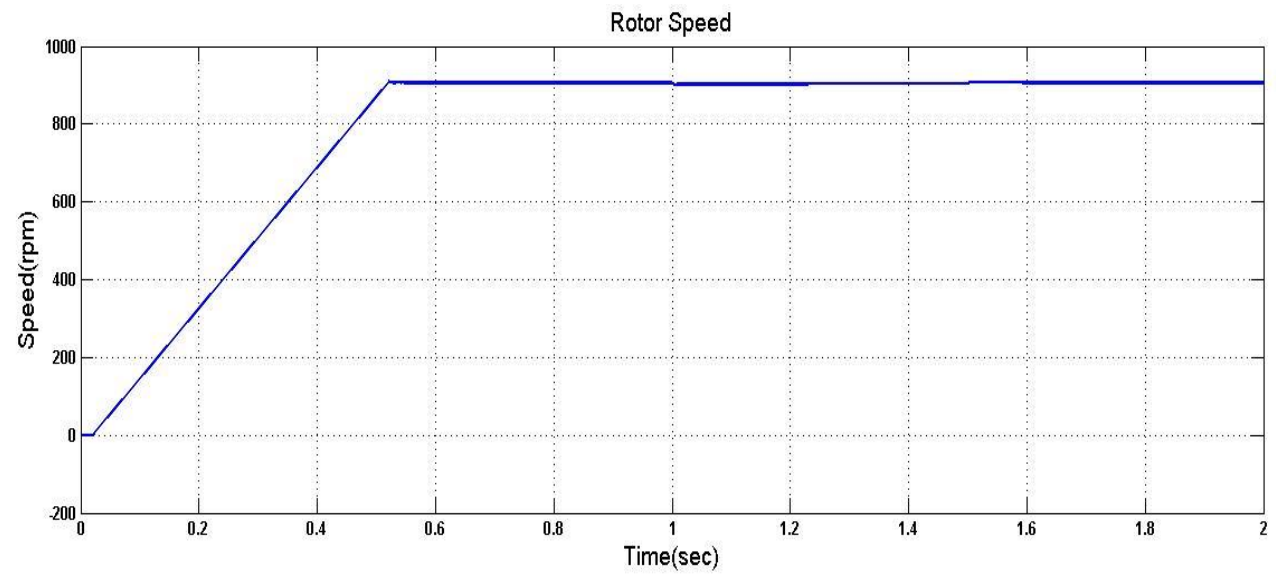

Figure 13. Rotor Speed for DTC using and replace PI ANN by replacing switching table

\subsubsection{Electromagnetic torque results}

Figures 14-17 show the results of electromagnetic torque for DTC. Figure 14 using classical, Figure 15 by using fuzzy logic. ANN shows in Figure 16 by replacing PI and in figure 17 by replacing the switching table.

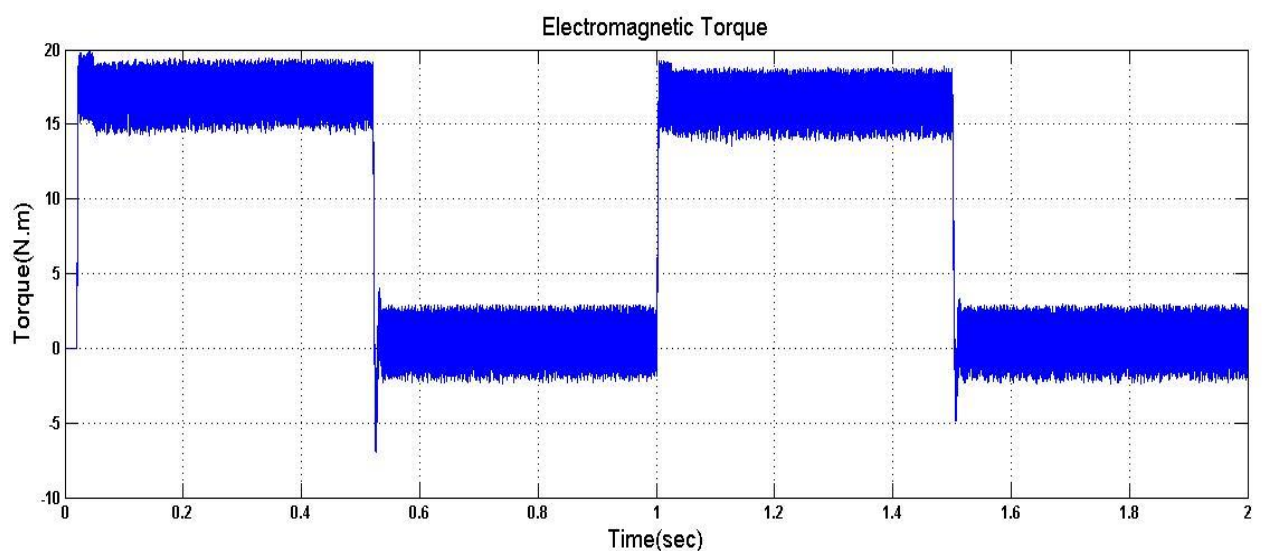

Figure 14. Electromagnetic Torque for the classical DTC 


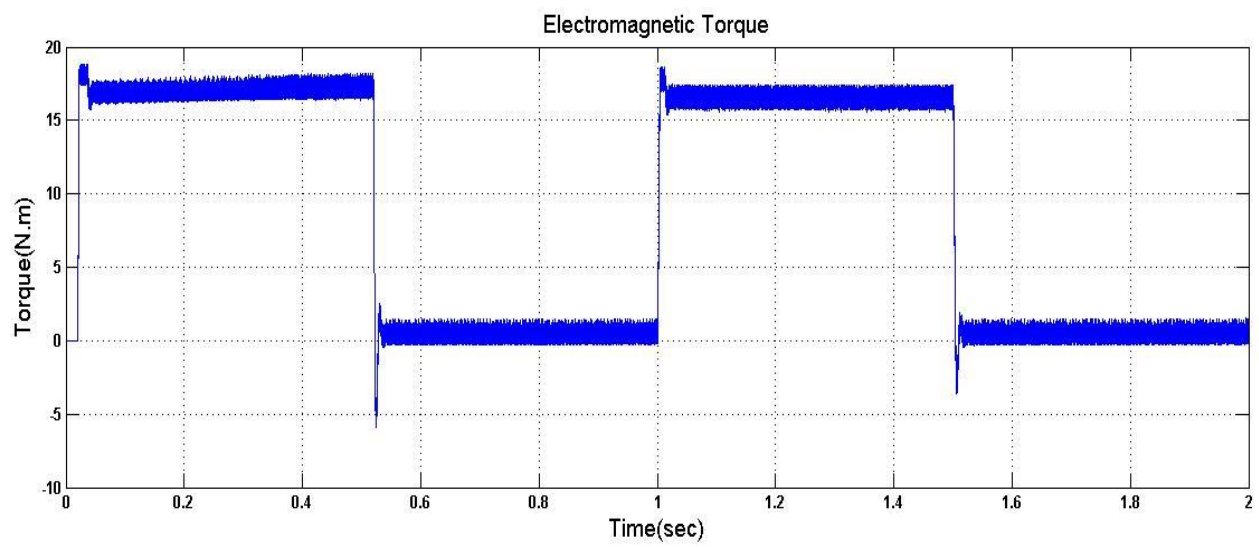

Figure 15. Electromagnetic Torque for DTC using fuzzy logic

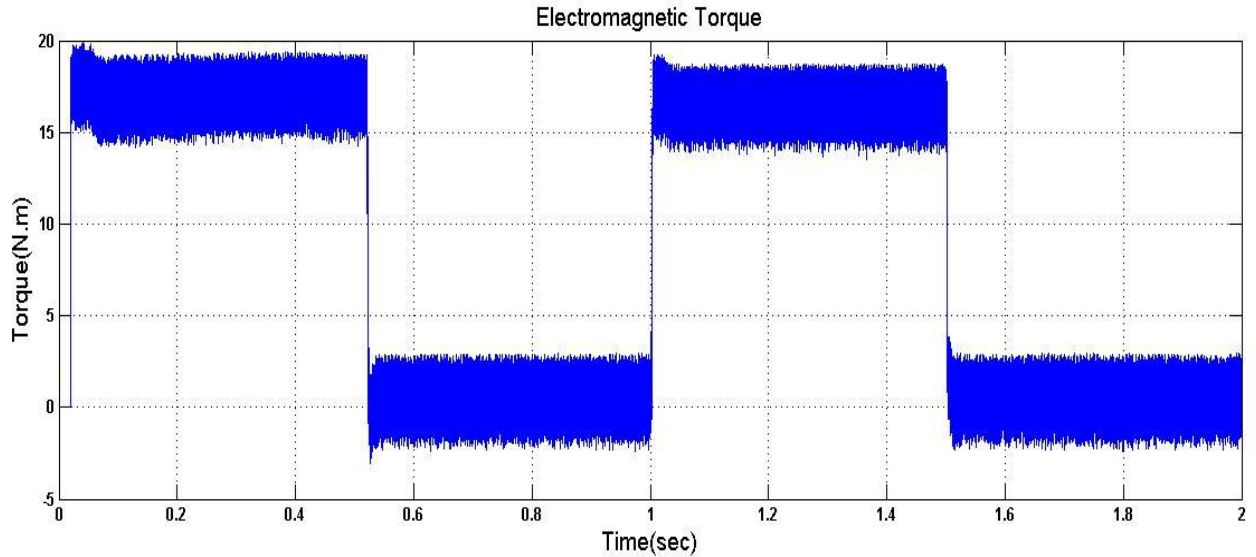

Figure 16. Electromagnetic Torque for DTC using ANN by replacing conventional PI

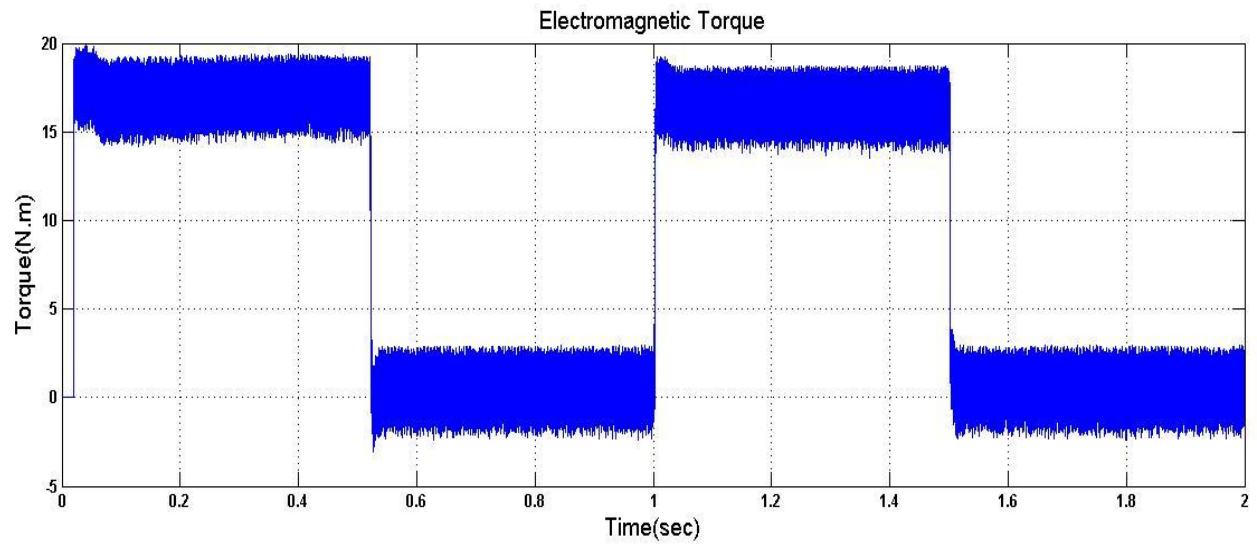

Figure 17. Electromagnetic Torque for DTC using ANN by replacing switching table

\subsubsection{Stator current results}

Figures 18-21 show the results of stator current for DTC. Figure 18 using classical, Figure 19 by using fuzzy logic. ANN shows in Figure 20 by replacing PI and in Figure 21 by replacing the switching table. 


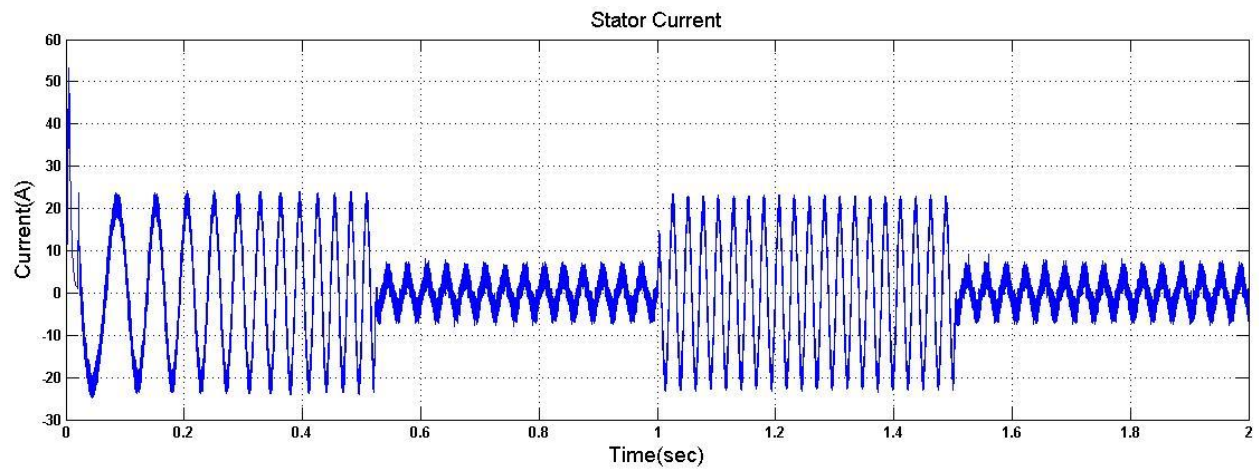

Figure 18. Stator current for the classical DTC

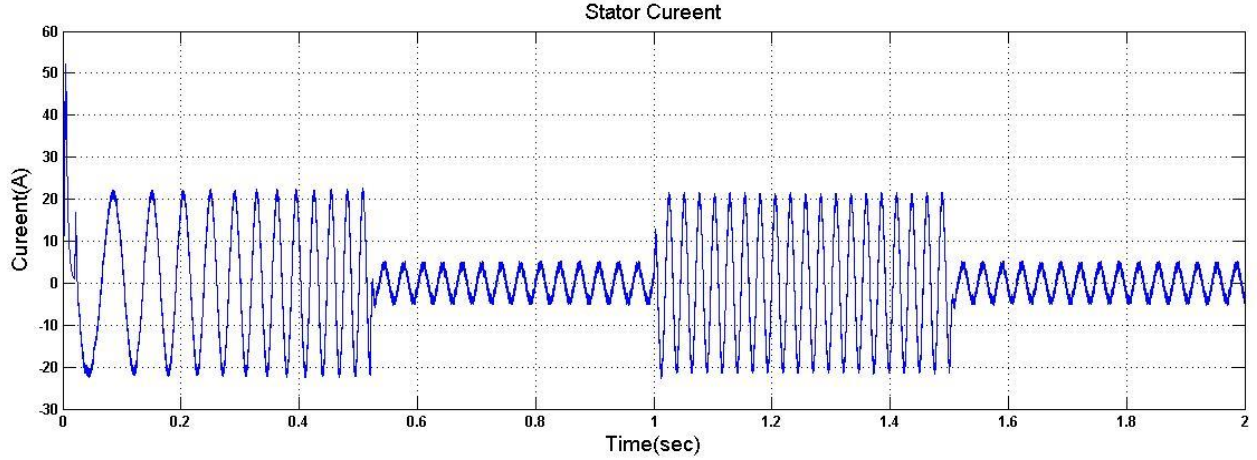

Figure 19. Stator current for the DTC using fuzzy logic

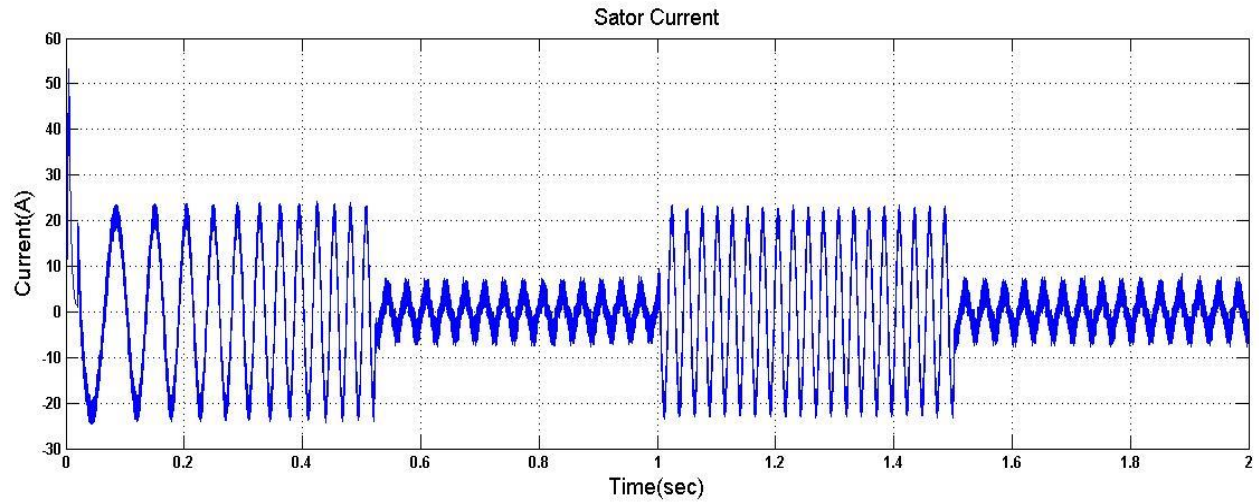

Figure 20. Stator Current for DTC using ANN by replacing conventional PI

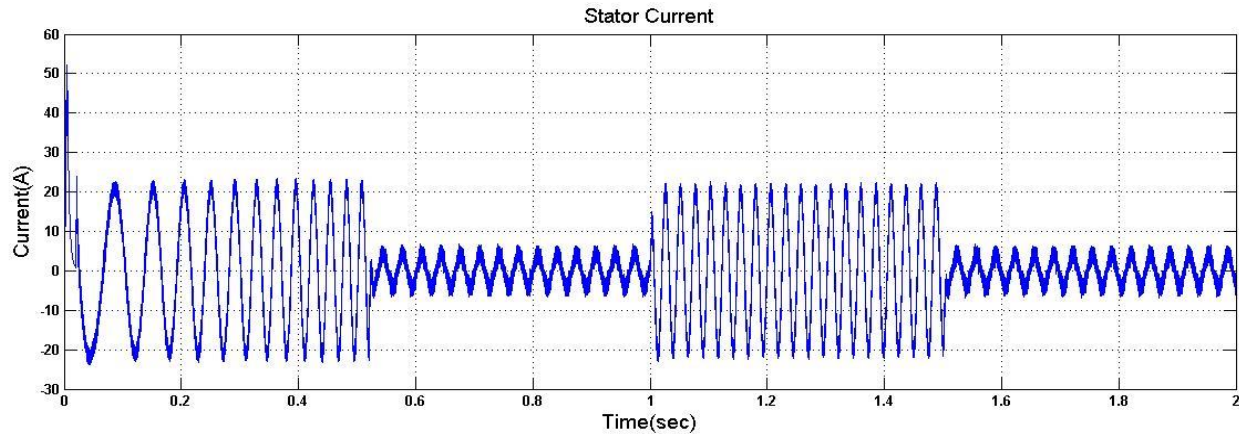

Figure 21. Stator Current for DTC using ANN by replacing switching table 


\subsubsection{Stator flux circle results}

Figures 22-25 show the results of stator flux circle for DTC. Figure 22 using classical, Figure 23 by using fuzzy logic. ANN shows in Figure 24 by replacing PI and in Figure 25 by replacing the switching table.

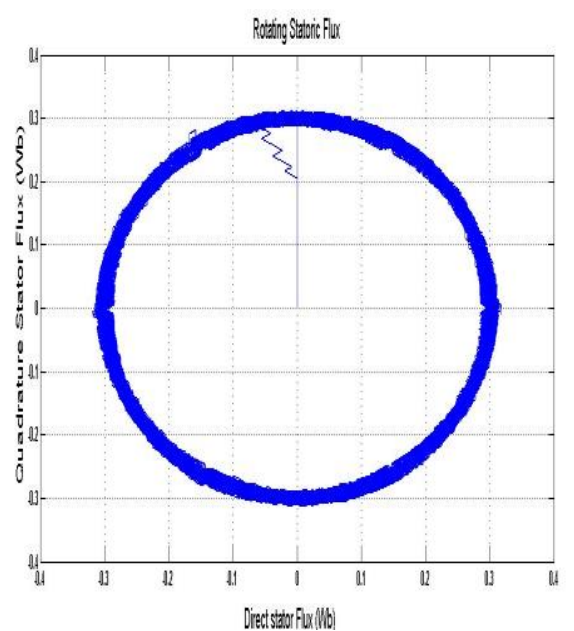

Figure 22. Stator flux circle for the classical DTC

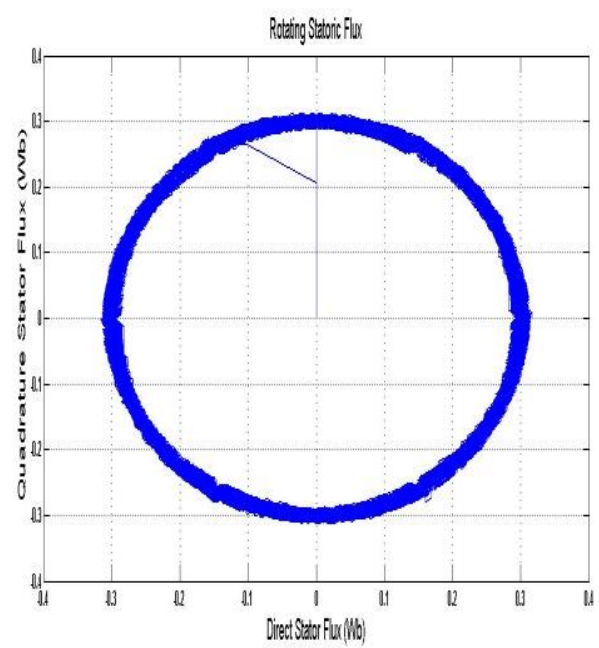

Figure 24. Stator flux circle for the DTC using ANN by replacing conventional PI

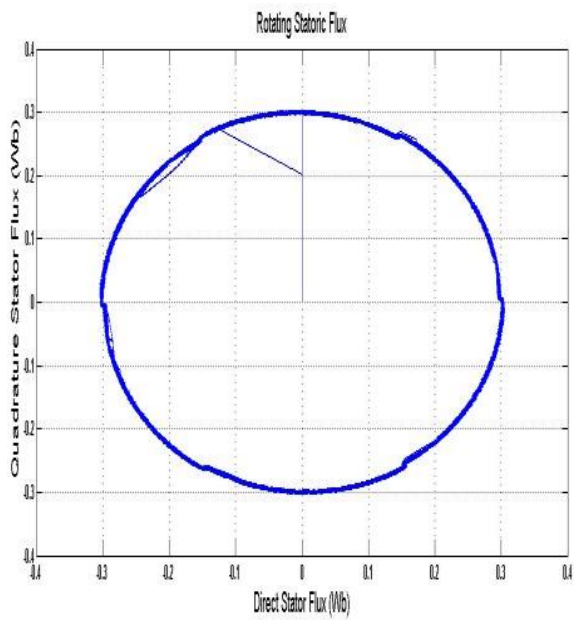

Figure 23. Stator flux circle for DTC using fuzzy logic

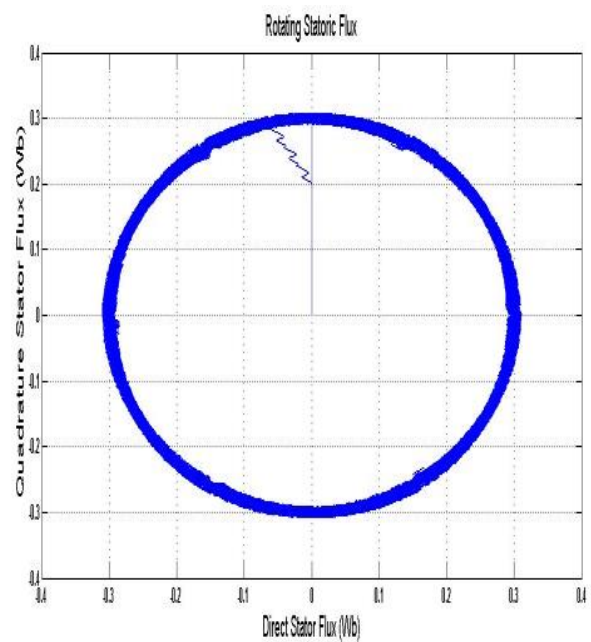

Figure 25. Stator flux circle for DTC using ANN by replacing switching table

\section{CONCLUSION}

Due to an importance method of the DTC for the IM drives its great performance and ease, so several strategies have been created aims to access the best results for IM. In this paper, to improve the DTC of IM, it's using the applications of AI techniques to reduce the ripples of current, torque, and flux. After testing the system with all three controllers (conventional DTC, FLC, and ANN) by using software MATLAB/Simulink. The simulation show the following results; 1) Fast dynamic response for different mentioned methods. 2) High torque ripple for conventional DTC. 3) ANN can be applied on DTC by: a) the switching table selector block, as well as the two hysteresis controllers, must be replaced. b) the conventional PI controller is being replaced. ANN results in the two methods are close to each other, it's considered beter than the conventional DTC. 4) It's noted that the FLC gives better responses from than the conventional DTC and the artificial neural networks. All results can be noted for all the controllers as shown in Table 3. 


\section{ACKNOWLEDGEMENTS}

In the the beginning, I'd to thanks my God for all blessings giving to me. Second, Thanks for my teacheres they are the best mentors to me. Dr Salama Abu-Zaid he is a fantastic personality and he is guide me in this paper. And too, I'd like to thanks my parents, brothers, husband, my son, and my friends for helping me.

\section{REFERENCES}

[1] H. Arabaci, and O. Bilgin, "Squirrel Cage of Induction Motors Simulation via Simulink," vol. 2, no. 3, p. 324-327, June 2012

[2] A. M. Ali, S. Z. Abo, and A. H. Ahmed, "Modified Single Phase Induction Motor Fed from The Solar Energy," Journal of Engineering and Applied Sciences, vol. 13, no. 16, pp. 6904-6909, October 2018, doi: 10.36478/jeasci.2018.6904.6909.

[3] K. Gottapu, Y. V. Prashanth, P. Mahesh, Y. Sumith, and P. S. Kiran, "Simulation of DTC IM Based on PI \& Artificial Neural Network Technique," International Journal of Advanced Research in Electrical, Electronics and Instrumentation Engineering, vol. 2, no. 7, pp. 3340-3348, July 2013.

[4] Ch. Chengaiah and I. P. Siva, "Performance of Induction Motor Drive by Indirect Vector Controlled Method Using Pi and Fuzzy Controllers," International Journal of Science, Environment and Technology, vol. 2, no. 3, pp. 457469, 2013.

[5] K. Parker, "Topic 13: Vector Control of AC Induction," ECE Electric Drives, April 2004

[6] V. Kumar, and S. Rao, "Modified Direct Torque Control of Three-Phase Induction Motor Drives with Low Ripple in Flux and Torque," Leonardo Journal of Sciences, no. 18, pp. 27-44, June 2011

[7] B. K. Bose, "Power Electronics and Motor Drives," Elsevier, 2010.

[8] I. Takahashi, and T. Noguchi, "A New Quick-Response and High-Efficiency Control Strategy of an Induction Motor," in IEEE Transactions on Industry Applications, vol. IA-22, no. 5, pp. 820-827, September 1986, doi: 10.1109/TIA.1986.4504799.

[9] P. Tiitinen, and M. Surandra, "The next generation motor control method, DTC direct torque control," Proceedings of International Conference on Power Electronics, Drives and Energy Systems for Industrial Growth, vol. 1, pp. 37-43, 1996, doi: 10.1109/PEDES.1996.537279.

[10] J.-Q. Yang, and J. Huang, "Direct torque control system for induction motors with fuzzy speed PI regulator," 2005 International Conference on Machine Learning and Cybernetics, vol. 2, pp. 778-783, 2005, doi: 10.1109/ICMLC.2005.1527049.

[11] M. K. Eldin, and S. Abo-Zaid, "Resistance Estimation for Sensor less Permanent Magnet Synchronous Motor Drives," International Journal of Engineering and Innovative Technology (IJEIT), vol. 5, no. 6, pp. 8-12, December 2015, doi: 10.17605/OSF.IO/D9VJG.

[12] R. Fuller, and R. Fullér, "Introduction to Neuro-Fuzzy Systems," Springer Science \& Business Media, 2000, doi: 10.1 007/978-3-7908-1852-9.

[13] K. Shi, T. F. Chan, and Y. K. Wong, "Modelling of the three-phase induction motor using SIMULINK," Conference: Electric Machines and Drives Conference Record, 1997. IEEE International, vol. 36, pp. 163-172, June 1997, doi: 10.1109/IEMDC.1997.604326.

[14] T. C. Fun and K. Shi, Applied Intelligent Control of Induction Motor Drives, John Wiley \& Sons, January 2011.

[15] P. Krause, O. Wasynczuk, S. D. Sudhoff, and S. Pekarek, "Analysis of Electric Machinery and Drive Systems," John Wiley \& Sons, vol 75, 2013.

[16] N. Mohan, Advanced Electric Drives, John Wiley \& Sons, 2014

[17] P. M. Menghal, and A. J. Laxmi, "Adaptive Neuro Fuzzy based dynamic simulation of induction motor drives," 2013 IEEE International Conference on Fuzzy Systems (FUZZ-IEEE), 2013, pp. 1-8, doi: 10.1109/FUZZ-IEEE.2013.6622452.

[18] P. M. Menghal, A. J. Laxmi, and N. Mukhesh, "Dynamic simulation of induction motor drive using artificial intelligent controller," Proceedings of the 2014 International Conference on Control, Instrumentation, Energy and Communication (CIEC), 2014, pp. 301-305, doi: 10.1109/CIEC.2014.6959098.

[19] R. S. Soni, and S S. Dharmal, "Direct Torque Control of Three Phase Induction Motor Using Fuzzy Logic," International Journal of Engineering Trends and Technology (IJETT), vol. 6, no. 3, pp. 161-167, Dec. 2013.

[20] M. Koshy, and M. A Lekshmi, "Direct Torque Control Schemes for Induction Motor,” Jan. 2011.

[21] R. Toufouti, S. Meziane, and H. Benalla, "Direct Torque Control Strategy of Induction Motors," Acta Electrotechnica et Informatica, vol. 7, no. 1, pp. 1-7, July 2007.

[22] V. M. V. Rao, and A. Anand Kumar, "Artificial Neural Network and Adaptive Neuro Fuzzy Control of Direct Torque Control of Induction Motor for Speed and Torque Ripple Control," 2018 2nd International Conference on Trends in Electronics and Informatics (ICOEI), 2018, pp. 1416-1422, doi: 10.1109/ICOEI.2018.8553871.

[23] A. Moualdia, D. Boudana, O. Bouchhida, and P. Wira, "Direct torque control based multi-level inverter and artificial neural networks of wind energy conversion system," 2016 8th International Conference on Modelling, Identification and Control (ICMIC), 2016, pp. 49-54, doi: 10.1109/ICMIC.2016.7804199.

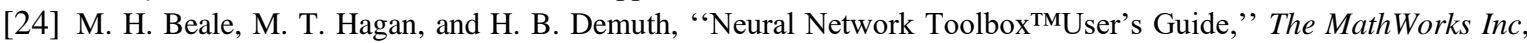
vol. 103, 1992. 
[25] M. Hamouda, S. Abo-Zaid, and Abd E. Kotb, "Sensor less DTC Using Artificial Intelligent Technique as Switching Vector Selector," vol. 7, no. 6, pp. 220-228, June 2016, doi: 10.13140/RG.2.2.22013.87526.

[26] A. Massoum, A. Meroufel, and Y. Djeriri, "Artificial Neural Network Based Direct Torque Control of Doubly Fed Induction Generator," vol. 14, no. 2, p. 8, June 2014.

\section{BIOGRAPHIES OF AUTHORS}

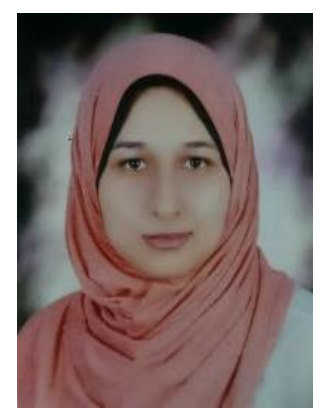

Mona Magdy Ragab was born in 6 june 1992 in Tanta (Egypt). She graduated from the Faculty of Engineering, Al Azhar University, Cairo, Egypt, Department of at Electrical Power and Machine, in 2015.

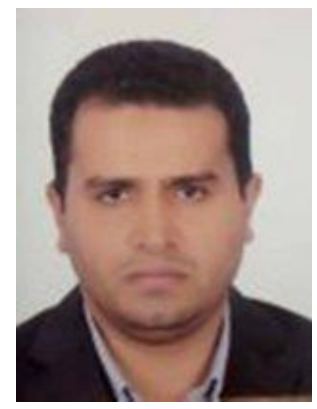

Salama Abu-Zaid, He is associated Professor, Head of Department of Electrical Power and Machine, Faculty of Engineering (Girls), Al Azhar University, Cairo, Egypt.

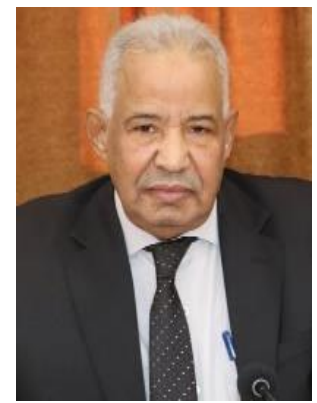

Mahmoud A. Elwany, He is aProfessor, Department of Electrical Machine, Faculty of Engineering (Girls), Al Azhar University, Cairo, Egypt. He was Former Dean of Girls Engineering from 2015 to 2019. 